\title{
Viable Bacteria Inside the Rumen Ciliate Entodinium caudatum
}

\author{
By R. W. WHITE \\ Biochemistry Department, Agricultural Research Council \\ Institute of Animal Physiology, Babraham, Cambridge
}

(Accepted for publication 3 March 1969)

SUMMARY AND INTRODUCTION

\begin{abstract}
Although bacteria are visible in Gram-stained smears of rumen entodinomorphid protozoa, no successful attempts to culture these bacteria have been reported. Gutierrez \& Davis (1959), using oligotrich protozoa from the calf rumen, cultured 3 to Io Streptococcus bovis per protozoon, after disruption by crushing between glass slides. The purpose of the present study was to investigate the viable bacterial flora of Entodinium caudatum which had originated from the sheep rumen, and had been maintained under constant conditions in vitro for over 6 years (Coleman, 1958, 1960). Part of the work has been reported previously (White, I966).
\end{abstract}

\section{METHODS}

The standard medium used for the enumeration, isolation, and maintenance of the bacteria from the disrupted protozoa was that of Bryant \& Robinson (I96I), containing $0.05,0.65$ or $\mathrm{I} .25 \mathrm{~g}$. of agar per $100 \mathrm{ml}$, for liquid medium, counting medium, or roll bottles, respectively. The reducing reagent contained per $100 \mathrm{ml}: \mathrm{Na}_{2} \mathrm{~S} .9 \mathrm{H}_{2} \mathrm{O}$, $2.5 \mathrm{~g}$., L-cysteine $2.5 \mathrm{~g}$, adjusted to $\mathrm{pH}$ II and autoclaved under $\mathrm{N}_{2}$ at II $5^{\circ}$ for $20 \mathrm{~min}$.; $0 . \mathrm{I} \mathrm{ml}$. of this with $0.4 \mathrm{ml}$. of sterile $8 \%$ (w/v) $\mathrm{Na}_{2} \mathrm{CO}_{3}$, and any other test substances in a volume of $0 . \mathrm{I}$ to $0.5 \mathrm{ml}$. were added to $9 \mathrm{ml}$. volumes of medium at $48^{\circ}$. Equilibration done with $\mathrm{CO}_{2}$ freed from $\mathrm{O}_{2}$ by passage over heated copper, and containers sealed with rubber stoppers. For the preparation of inoculum dilutions, sterile diluting fluid consisting of the standard medium described above, but without agar and with water substituted for rumen fluid was used.

Sodium azide was dissolved in sterile water at $\times 100$ the defined final concentration, before use.

Conventional unsealed media used for anaerobic culture were freshly prepared, and incubated under $5 \% \mathrm{CO}_{2}+95 \% \mathrm{H}_{2}(\mathrm{v} / \mathrm{v})$. Aerobic bacteria were maintained on Oxoid nutrient agar and broth (Oxoid Division of Oxo Ltd., Thomas House, Queen Street Place, London, E.C.4). All cultures were incubated at $39^{\circ}$.

Extracts for streptococcal grouping were prepared by the acid extraction method of Lancefield (1933). Tests for production of arginine dihydrolase and for deamination of phenylalanine were as described by Whitfield (1967), for lysine and ornithine decarboxylases and the production of visible gas at $44^{\circ}$ according to Cowan \& Steele (1965). Motility was observed in hanging-drop preparations from liquid cultures taken as soon as visible growth occurred. Suspensions of bacteria from the water of condensation of agar slope cultures were mixed with indian ink and examined for capsule 
formation. Flagella and fimbriae were observed with the electron microscope using the negative staining technique. Three day old cultures in nutrient broth containing $0.5 \%$ (w/v) glucose and in the lactate medium of Sundman \& Björksten (I958) were examined by gas/liquid chromatography for the production of volatile fatty acids, by the procedure of Emery \& Koerner (I96I).

The terms 'aerobe' and 'aerobic' are used to define bacteria which grow freely in the presence of gaseous oxygen, whether or not they also grow well under anaerobic conditions. An 'anaerobe' is defined as an organism which cannot grow in the presence of gaseous oxygen.

The protozoa were supplied by G. S. Coleman, they were cultured and inoculum suspensions prepared first as described by Coleman (I960, 1964), then transferred to sterile tubes, washed three times in sterile Coleman (1960, 1964) buffer solution containing $0 \cdot I \%(\mathrm{w} / \mathrm{V})$ L-cysteine, on the centrifuge, and resuspended at a population density of 2 to $5 \times 10^{5} / \mathrm{ml}$. One $\mathrm{ml}$. of this suspension, free of extracellular bacteria, was placed in a sterile corked 2 in. $\times \frac{1}{2}$ in. tube, immersed to the depth of the contained suspension in the water in a three-pint ultrasonic cleaning bath driven by an $80 \mathrm{kcyc} . / \mathrm{sec}$., $80 \mathrm{~W}$. generator (Kerry Ltd., Chester Hall Lane, Basildon, Essex). The bath was tuned to maximum cavitation before immersing the protozoal suspension. The number of viable bacteria was determined before and after sonic treatment of the protozoa by serial tenfold dilution followed by inoculation in triplicate into the standard Bryant \& Robinson solid counting medium contained in modified Carrel (I923) flasks having a $12 \mathrm{~mm}$. deep circular chamber of Io to I I $\mathrm{ml}$. capacity and a straight neck, made to specification by Wesley Coe (Cambridge) Ltd., Scotland Road, Cambridge. After 3 days incubation, colony counts were done on flasks showing more than Io and less than 300 colonies. Counts of protozoa before and after disruption, were done by suitable dilution in $0.02 \mathrm{M}$-iodine and all protozoa in $0.1 \mathrm{ml}$. counted under the phase-contrast microscope.

\section{RESULTS}

The effect of increasing times of sonic treatment on the number of protozoa and of viable bacteria per protozoon is shown in Fig. I. From this the $5 \mathrm{sec}$. period of treatment was chosen and used routinely on 30 samples of the protozoa taken at approximately weekly intervals; the number of viable bacteria obtained was $2 \mathrm{I} \cdot 8 \pm 8 \cdot 2$ per protozoon. Before sonic treatment the number of viable bacteria per protozoon was always very close to $\mathrm{I}$, as would be expected.

In a series of 30 triplicate viable bacterial counts at various levels of broken protozoa, the scatter of reciprocals of mean counts were all within $20 \%$ and mainly within $10 \%$ (Fig. 2).

Most of the bacteria found were Gram-negative aerobes which were readily isolated on nutrient agar plates but rapidly over-grew the less numerous organisms in roll bottles. To overcome this for isolation purposes, sodium azide was found to be the best of a number of selective inhibitors, including antibiotics, which were tried. Sodium azide $500 \mu \mathrm{g} / \mathrm{ml}$, with seed dilutions of $1^{-2}$ and $10^{-3}$ was used in roll bottles of the standard medium. Under these conditions, to achieve satisfactory reduction, as judged by decolorization of the resazurin, the concentration of L-cysteine was raised to $0.5 \mathrm{mg}$. $/ \mathrm{ml}$. (Margherita \& Hungate, 1963). From these roll bottles, 
single colonies were seeded in the standard liquid medium and examined. A number of each morphological type found were again twice put through roll bottles and single colonies picked off, examined for purity and for identification. Nine species of bacteria were isolated, placed in groups for convenience, as follows:

Aerobic Gram-negative bacteria. From 69 strains, two kinds emerged designated I7G I and I7G 5A. Organism I7G I is a member of the genus Klebsiella because of lactose fermentation, capsule formation, production of lysine decarboxylase, absence of motility and inability to form indole it is assigned to $K$. aerogenes species on the basis of dulcite fermentation, negative methyl-red and positive Vosges-Proskauer reaction. No fimbriae were found and the $44^{\circ}$ test was positive. Cowan \& Steele

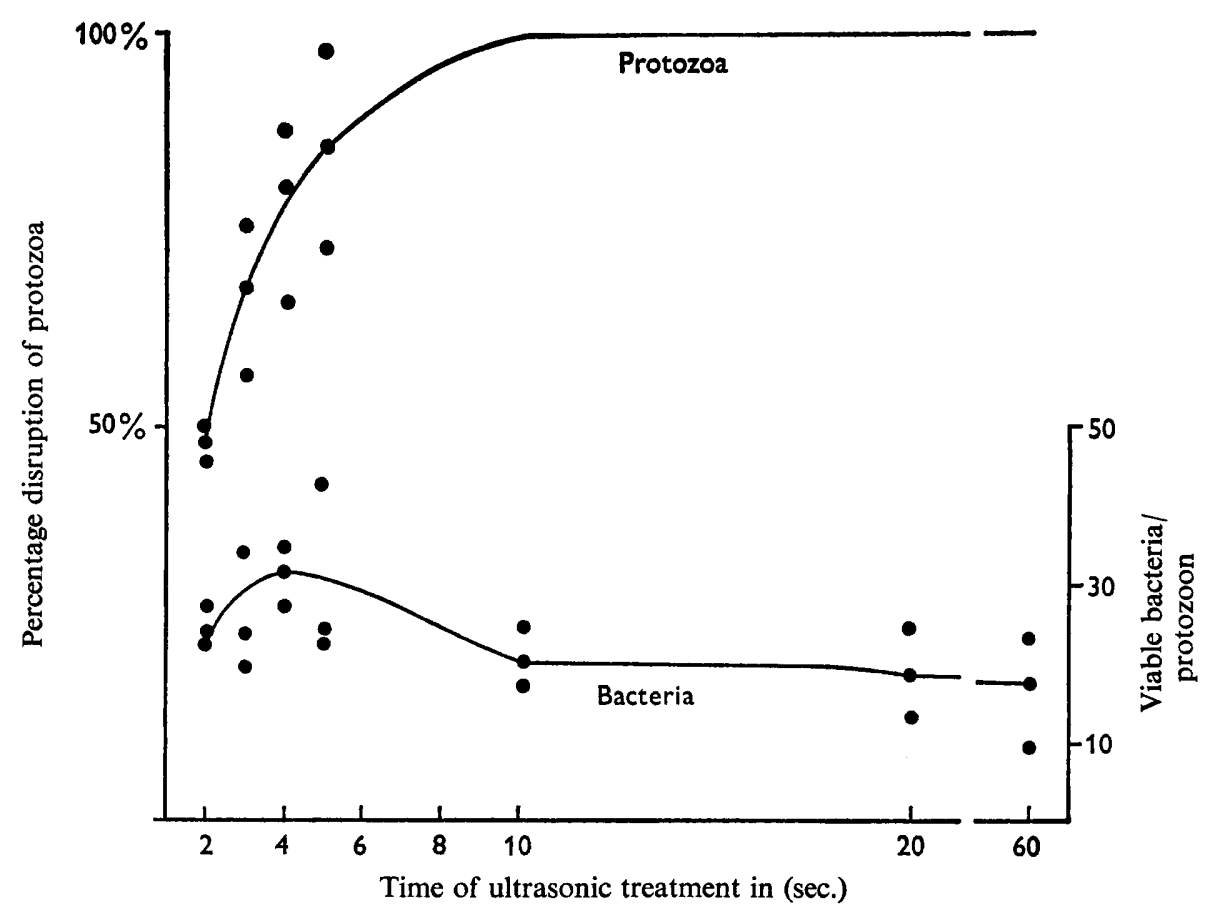

Fig. I. Relationship of the degree of disruption of $E$. caudatum with numbers of released bacteria viable after treatment by bath ultrasonic treatment for 2 to $60 \mathrm{sec}$.

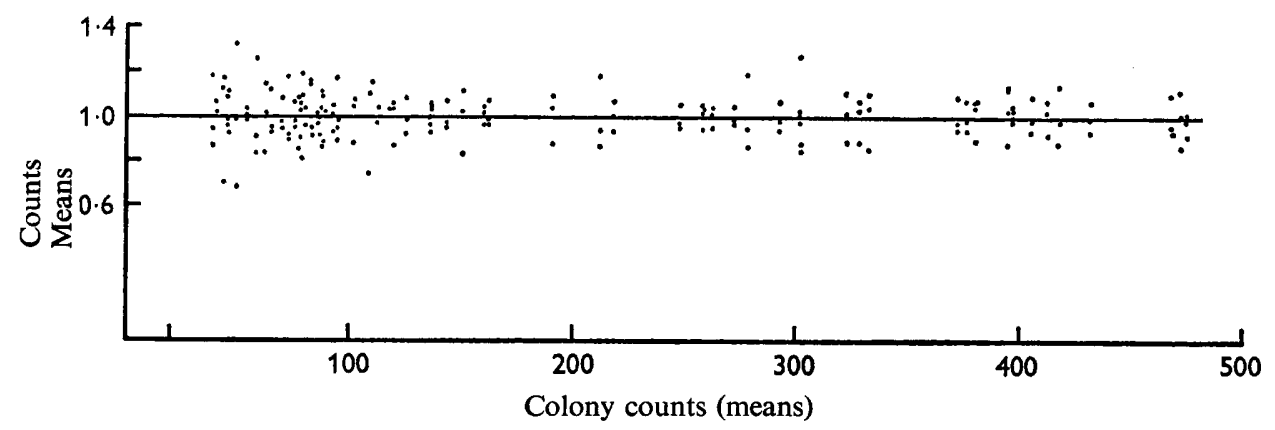

Fig. 2. Reciprocals (counts/means) of bacterial colony counts (triplicate) from disrupted $E$. caudatum, plotted to show variations around means over a range. Results from 30 experiments. 
(I960) reported that $50 \%$ strains were $44^{\circ}$ positive and predicted the occurrence of nonfimbriate varieties. Organism 17 G 5 A was identifiable as a member of the genus Proteus because of motility with peritrichous flagella, and the ability to deaminate phenylalanine (Whitfield, 1967). It was assigned to $P$. mirabilis on the basis of sucrose fermentation, decarboxylation of ornithine and failure to produce indol.

Anaerobic Gram-negative bacteria. Two kinds were isolated, designated 7 P 1 and $22 \mathrm{G} 33 \mathrm{C}$. Organism 7 P I was a small curved rod, motile with a single very long subpolar flagellum. It was fermentatively active, neither produced nor utilized lactate, and produced butyric acid freely from glucose (Table I). It is assigned to the genus Butyrivibrio with no species identification. Bryant (1959) reported that only a proportion of butyrivibrio strains of ruminal origin fermented cellulose. Hungate (I966) placed strains not producing lactate in a new species $B$. alactacidigens, however, the pattern of substrate fermentation he described was not exhibited by 7 P I. Organism 22 G 33 C, a small slender rod, initially grew slowly in groups, but after repeated subculture good growth of separate bacteria occurs. As a non-motile bacterium, which hydrolysed casein, produced small amounts of lactic acid, but a trace of acetic acid only from glucose (Table I) this organism is assigned to the genus Bacteroides. Absence of succinic acid production from glucose, and of amylolytic activity remove it from the commonly described rumen species; no species identification is offered.

Table I. Production of volatile fatty acids by isolated bacteria ( $m$-moles per Ioo ml. substrate)

\begin{tabular}{lllll}
\multicolumn{1}{r}{ Strain } & Substrate & Acetic & Butyric & Propionic \\
7 P I & Glucose & 0 & 0.31 & 0.03 \\
& Lactate & 0 & 0 & 0 \\
22G 33C & Glucose & 0.06 & 0 & 0 \\
& Lactate & 0.03 & 0.02 & 0 \\
& Glucose & $0.34 / 0.29$ & $0.59 / 0.31$ & $0 / 0$ \\
41 NT 16 2* & Lactate & $0.54 / 0.52$ & $0.66 / 0.55$ & $0 / 0$ \\
& Glucose & $0.19 / 0.43$ & $0 / 0$ & $1 \cdot 10 / 1.25$ \\
& Lactate & $0.11 / 0.24$ & $0 / 0$ & $0.50 / 0.68$
\end{tabular}

Gram-positive bacteria. Two kinds were isolated, designated 15N 2 and 4I G T 162. Organism $15 \mathrm{~N} 2$ was frequently encountered closely associated with the Butyrivibrio 7P I, from which it was difficult to separate even in single colony picks. It was a pleomorphic bacterium, bifid forms occurred, and agar slopes of the media described by Sundman, Björksten \& Gyllenberg (1959) supported good growth of clubbed and irregular rods under anaerobic conditions only. It was fermentatively relatively inactive, utilized lactate freely and produced quantities of butyric acid from glucose or lactate (Table I), and is a Butyribacterium. It differs from the single species member, $B$. rettgeri (Barker \& Haas, 1944) in not surviving $60^{\circ}$ for $30 \mathrm{~min}$.

Organism 4I GT I6 2 was a pleomorphic rod which grew very slowly in the standard medium to form tangled masses. Agar slopes of the Sundman et al. (I959) media supported growth of clubbed and beaded rods and on their ' $G$ ' agar and 'C.Y.E.' agar slopes this occured equally well under aerobic or anaerobic conditions; this was therefore an 'aerobe'. The organism survived $60^{\circ}$ for $30 \mathrm{~min}$., grew freely at $\mathrm{pH} 5.0$, and pro- 
duced lactic acid and large amounts of propionic acid from glucose (Table I). It is assigned to the genus Propionibacterium (Bergey's Manual, 1948) with no species identification.

Streptococci. Three organisms were found, designated I5N I, I6N I8 and $20 \mathrm{G} \mathrm{I}$. None showed haemolysis in horse blood agar plates or survived $60^{\circ}$ for $30 \mathrm{~min}$., all three displayed haemolysins in a tube test and grew at $\mathrm{pH} 9 \cdot 6$. Extracts of organisms I6N I 8 and $20 \mathrm{G}$ I reacted with grouping sera of Lancefield groups D and N. Organism I $6 \mathrm{~N} \mathrm{I} 8$ was aerobic, grew at $45^{\circ}$ and fermented raffinose, organism $20 \mathrm{G}$ I was anaerobic and failed to grow at $45^{\circ}$ or to ferment raffinose. Both are assigned as strains of Streptococcus bovis. Perry, Newland \& Briggs (1958) recorded the occurrence of crossreactions between Lancefield groups $\mathrm{D}$ and $\mathrm{N}$ in strains of $S$. bovis from the rumen. Organism I5N I was a small streptococcus, extracts of which reacted with serum of Lancefield group $\mathrm{G}$ only. It failed to grow at $45^{\circ}$ or to ferment raffinose; it produced ammonia from arginine. No species definition is offered.

Numerical relationships. To establish relationship between total numbers of intracellular and extracellular viable bacteria samples of Coleman's (1958, 1962) surrounding protozoal medium taken from his protozoa cultures were examined by the same bacterial counting method and medium as for the disrupted protozoa. Viable bacterial counts of between 98 and $267 \times 10^{5} / \mathrm{ml}$. were obtained in eleven experiments in which the counts of protozoa were between 22 and $31 \times 10^{3} / \mathrm{ml}$. From this can be calculated a figure of approximately 20 times as many viable bacteria per protozoon outside as inside the protozoa.

Attempts were also made to determine the ratio of the fast growing aerobic bacteria to the other organisms inside the protozoa by parallel aerobic and anaerobic counts, and by parallel roll bottle counts, with and without sodium azide. The first method gave a ratio of 3 to $I$, the second method 13 to $I$.

The ratio of Klebsiella aerogenes to Proteus mirabilis in the protozoa was determined by using the sensitivity of the latter to chloramphenicol determined on the isolated strains, when a concentration of $50 \mu \mathrm{g} / \mathrm{ml}$. decreased numbers of $K$. aerogenes from 418 to $2 \times 10^{7}$, whereas the $P$. mirabilis was unaffected. Aerobic counts on the disrupted protozoa suspension were decreased by $30 \%$ in the presence of chloramphenicol, this was taken to indicate a ratio of approximately 2 to I, $K$. aerogenes to $P$. mirabilis.

\section{DISCUSSION}

The bacterial flora in Coleman's protozoa culture tubes have become established over a long time, and under maintenance conditions which allow free entry of adventitious organisms, so that the environment has determined the pattern. Some of the bacteria isolated notably the Butyrivibrio and Bacteroides might have originated from the rumen. The Klebsiella aerogenes and Proteus mirabilis exerted a powerful reducing effect in the protozoa cultures.

Coleman (1964) showed that bacteria were engulfed and rapidly digested by his Entodinium caudatum in culture, and that differences in survival were not related to any obvious character or to the source of the bacteria. Coleman \& Hall (I966) suggested that bacteria ingested by the protozoa might be taken whole into the cytoplasm and broken down there.

No real evidence emerges of recognizable colonization of the interior of the protozoa 
by bacteria. If these were nidated inside, wide fluctuations in numbers might be expected, according to how far colony masses had become variably dispersed during disruption of the protozoa. The maximum possible number of the most numerous bacterium per protozoon can be calculated as 7 Klebsiella aerogenes, which is too low to interpret unequivocally as colonisation. It is most likely that the viable bacteria cultured were those which had been swept in by the protozoal cilia, possibly into an antrum but which had not progressed into the body of the protozoa at the time when these are disrupted.

Thanks are due to Drs P. F. V. Ward and P. Kemp for gas/liquid chromatograph estimations of volatile fatty acids, to Dr E. Munn for electron micrographs, to $\mathrm{Mr}$ G. A. Embleton for the insertion of permanent rumen cannulae in sheep, and to Mrs M. E. Black for invaluable technical assistance. Dr G. S. Coleman supplied his cultures of E. caudatum and much helpful criticism.

\section{REFERENCES}

BARKER, H. A. \& HAAS, V. (1944). Butyribacterium, a new genus of Gram-positive, non-sporulating, anaerobic bacteria of intestinal origin. J. Bact. 47, 30I.

Bergey's Manual of Determinative Bacteriology (1948), 6th ed. Baltimore: Williams and Wilkins Co. BRYANT, M. P. (1959). Bacterial species of the rumen. Bact. Rev. 23, 125.

BRYANT, M. P. \& Robinson, I. M. (I96I). An improved non-selective culture medium for ruminal bacteria. J. Dairy Sci. 44, 1446.

Carrel, A. (1923). A method for the physiological study of tissues in vitro. J. exp. med. 38, 407.

Coleman, G. S. (1958). Maintenance of oligotrich protozoa from the sheep rumen in vitro. Nature, Lond. 182, I IO4.

Coleman, G. S. (1960). The cultivation of sheep rumen oligotrich protozoa in vitro. J. gen. Microbiol. 22, 565 .

Coleman, G. S. (1962). The preparation and survival of almost bacteria free suspensions of Entodinium caudatum. J. gen. Microbiol. 28, 271.

Coleman, G. S. (1964). Metabolism of Escherichia coli and other bacteria by Entodinium caudatum. J. gen. Microbiol. 37, 209.

Coleman, G. S. \& Hall, F. J. (1966). The digestion of bacteria by the rumen ciliate Entodinium caudatum. J. gen. Microbiol. 44, iii.

Cowan, S. T. \& Steele, K. J. (I960). A classification of the Klebsiella group. J. gen. Microbiol. 23, 601 .

Cowan, S. T. \& STEele, K. J. (I965). Manual for the Identification of Medical Bacteria. Cambridge University Press.

EMERY, E. M. \& KoERner, W. E. (196I). Gas chromatographic determination of trace amounts of the lower fatty acids in water. Analyt. Chem. 33, 146.

Gutierrez, J. \& DAvis, R. E. (1959). Bacterial ingestion by the rumen ciliates Entodinium and Diplodinium. J. Protozool. 6, 222.

Hungate, R. E. (1966). The Rumen and its Microbes. New York: Academic Press Inc.

LANCEFIELD, R. C. (1933). A serological differentiation of human and other groups of haemolytic streptococci. J. exp. med. $\mathbf{5 7}, 571$.

MARgherita, S. S. \& Hungate, R. E. (1963). Serological analysis of Butyrivibrio from the bovine rumen. J. Bact. 86, 855 .

Perry, K. D., Newland, L. G. M. \& Briggs, C. A. E. (1958). Group D rumen streptococci with type antigens of group N. J. Path. Bact. 76, 589.

Sundman, V. \& BJÖRKSTEN, K. af. (1958). The globular involution forms of the bifid bacteria. J. gen. Microbiol. r9, 491.

SundmAN, V., BJörksten, K. af. \& GYLLINBERG, H. G. (1959). Morphology of the bifid bacteria and some related genera. J. gen. Microbiol. 21, 37 I.

White, R. W. (1966). Bacterial population of a rumen ciliate Entodinium caudatum cultured in vitro. J. gen. Microbiol. 42, xii.

WHITFIELD, E. (1967). Rapid identification of coliform organisms from extra-intestinal infections. J. med. lab. Tech. 24, I7I. 